\title{
Theatre sending: how long does it take and what is the cost of late starts?
}

\author{
U. Walsh $\cdot$ F. Alfhaily $\cdot$ R. Gupta $\cdot$ D. Vinayagam • \\ B. Whitlow
}

Received: 21 January 2010 / Accepted: 24 February 2010 /Published online: 30 March 2010

(C) Springer-Verlag 2010

\begin{abstract}
This study seeks to identify areas of poor utilisation of theatre time and estimate the cost of late starts. Retrospective study of elective gynaecological operations from September to November 2008 in a district general hospital was conducted. Primary outcome measures were time to send, time for anaesthesia and procedure time. Secondary outcome measures were time to send for the first patient and cost of late starts $(N=164)$. The mean time to send was $19 \pm 8.10 \mathrm{~min}$ (95\% CI: $18-20)$. The mean time for anaesthesia was $9 \pm 6.40 \min (95 \% \mathrm{CI}: 7.91-9.86)$. The mean procedure time was $60 \pm 35$ (95\% CI: 55-65). On average time to send for the first patient on the morning list took $20 \pm 9.83 \mathrm{~min}(95 \% \mathrm{CI}: 17-23)$ and resulted in $93 \%$ of lists starting late. The surgical team waited a mean of $22 \pm$ 19 min (95\% CI: 17-27) for the first patient to arrive after the list was due to start. Total time wasted on late starts was $910 \mathrm{~min}(15 \mathrm{~h})$, costing an estimated $£ 3,640$ over the 3 -month period. This figure is based on local theatre staff wages of $£ 236.30$ per hour. Sending for patients $30 \mathrm{~min}$ before the list is due to start is an auditable standard that could increase theatre efficiency and enable $15 \mathrm{~h}$ of currently wasted resources to be used to shorten waiting lists and enhance staff training opportunities.
\end{abstract}

Keywords Theatre efficiency - Cost of late starts . Elective surgery $\cdot$ Surgical training

\footnotetext{
U. Walsh · F. Alfhaily • R. Gupta • D. Vinayagam •

B. Whitlow $(\square)$

Department of Obstetrics and Gynaecology, Colchester Hospital, Colchester Hospital University Foundation Trust, Colchester, UK

e-mail: barry.whitlow@colchesterhospital.nhs.uk
}

\section{Introduction}

The government's plan for the NHS is shorter waiting lists and increased patient choice $[1,2]$. In contrast, the NHS reality is that there were 63,644 last minute operation cancellations in 2008/2009, 6,294 (11\%) more than in $2007 / 2008$ [3]. Studies show, this translates to between $10 \%$ and $40 \%$ of elective operations maybe cancelled [4-7]. Inevitably this means longer waiting lists, less time for teaching and is a costly waste of resources. Foundation trusts face a particularly high burden of cost as National Contracts require NHS Trusts who are unable to rebook patients for a date within 28 days of their cancellation to fund the treatment at a time and place (e.g., private hospital) chosen by the patient [8]. It is equally important to recognise the cost of cancelled operations to patients who undoubtedly plan their work and family commitments around planned operation dates. Studies have shown that patients have a high level of emotional involvement before surgery and react negatively to cancellations particularly when they are due to organisational factors $[8,9]$.

Reasons for cancellations can be roughly divided into non-modifiable patient factors, i.e., the patient cancels or is unfit to undergo the procedure and modifiable system factors relating to poor theatre time utilisation such as late starts, overrunning lists and no separate emergency list disrupting theatre time [6]. A number of studies have demonstrated the extent of poor utilisation of theatre time, showing in some cases that $50 \%$ of lists over-ran their scheduled time [10] and $43.6 \%$ started late [12].

In an effort to improve efficiency and theatre time utilisation, the national theatre audit group carried out a review of theatre practises across 70 trusts [4]. They found that in many cases theatre managers were unable to improve efficiency or set targets because of a lack of 
recorded key information in relation to how theatres were run. On the basis of this they recommend that as a first step in improving theatre efficiency trusts investigate practises at a local level to identify and address areas of inefficient practise. In order to do so, emphasis should be placed on identifying and capturing information needed to plan and run an efficient operating theatre.

In line with this recommendation, a recent prospective study of 55 elective gynaecological operations showed that on average a quarter of the theatre session was wasted by delays in patient throughput, namely, transferring patients to and from the operating theatre. This resulted in a median waiting time of $22.5 \mathrm{~min}$ between cases for surgeons and 7 min for anaesthetists [13].

Adding to the current body of research in this area this study aims not only to examine the patient journey through theatres but also to extend the sample size and calculate the cost of delays in transit, focusing in particular on the cost of late starts where the surgical team are waiting for the first patient, past the agreed start time. This will then inform future theatre workload planning.

\section{Methods}

We conducted a retrospective study of the theatre transit of patients undergoing elective gynaecological operations over a 3-month period (September to November 2008) at a single district general hospital. Patients were admitted to a gynaecological ward situated one floor below the operating and recovery complex. Patients were brought to theatres on their bed accompanied by a nurse and porter. Time point data for each patient's journey through theatres was collected from theatre slips. Primary outcome measures were time to send (time of sending to time of arrival in anaesthetic room), time for anaesthesia (time of arrival in anaesthetic room to time of arrival in theatres), and procedure time (time of arrival in theatres to end of procedure). Secondary outcome measures included time to send for the first patient and late starts calculated as the time spent waiting after the list should have started. Finally the cost of late starts was calculated. All analysis was carried out in Microsoft Office Excel.

\section{Results}

A total of 238 elective gynaecological operations took place during the 3-month study period. Sixty-four cases were excluded from analysis due to incomplete time point data. Ten further cases were excluded as they were not carried out under general anaesthetic. The total number of cases
Table 1 Patient age and nature of surgery

\begin{tabular}{ll}
\hline Mean age & 55 years $(21-91)$ \\
Nature of Surgery $(N=164)$ & \\
Hysteroscopy & 25 \\
Laparoscopy & 21 \\
Laparotomy & 49 \\
Vaginal surgery & 69 \\
\hline
\end{tabular}

included in the analysis was 164 . Patient age and the nature of surgery can be seen in Table 1 .

Time point data

On average it took 19 min between sending for a patient and their arrival in the anaesthetic room (time to send), range 7 to $50 \mathrm{~min}$. The mean time for administering anaesthesia (time for anaesthesia) was less, on average taking 9 min with a range of 5 to $40 \mathrm{~min}$.

Overall the mean time to get a patient to the operating room from time of sending (total time to operating room) was $35 \mathrm{~min}$, range $10-85 \mathrm{~min}$. The procedure time took on average $60 \mathrm{~min}$ with a range of $10-190 \mathrm{~min}$. This data shows that apart from the procedure time the largest block of time is accounted for by getting the patient to the operating room. The majority of this time is spent getting the patient from the ward to the anaesthetic room Table 2 .

\section{Procedure time}

On average it took $86 \mathrm{~min}$ to perform a laparotomy, $54 \mathrm{~min}$ for vaginal surgery, $64 \mathrm{~min}$ for a laparoscopy and $25 \mathrm{~min}$ for a hysteroscopy Table 3

\section{Grade of surgeon}

The majority of the operations were carried out by senior surgeons (consultants-56\%, staff grades-21\%). Registrars carried out only $23 \%$ of procedures.

Table 2 Time point data

\begin{tabular}{lllll}
\hline $\begin{array}{l}\text { Time in } \\
\text { minutes }\end{array}$ & $\begin{array}{l}\text { Time } \\
\text { to send }\end{array}$ & $\begin{array}{l}\text { Time for } \\
\text { anaesthesia }\end{array}$ & $\begin{array}{l}\text { Total time to } \\
\text { operating room }\end{array}$ & $\begin{array}{l}\text { Time for } \\
\text { procedure }\end{array}$ \\
\hline Mean & 19 & 9 & 35 & 60 \\
Range & $7-50$ & $3-40$ & $10-85$ & $10-190$ \\
SD & 8.10 & 6.40 & 12 & 35 \\
CI (95\%) & $18-20$ & $8-10$ & $33-37$ & $55-65$ \\
\hline
\end{tabular}


Table 3 Procedure times

\begin{tabular}{lllll}
\hline Procedure & Hysteroscopy & Laparoscopy & Laparotomy & Vaginal surgery \\
\hline$N$ & 25 & 21 & 49 & 69 \\
Mean procedure time & 25 & 64 & 86 & 54 \\
Range & $10-55$ & $25-190$ & $35-160$ & $10-175$ \\
SD & 12 & 41 & 30 & 28 \\
CI $(95 \%)$ & $20-30$ & $46-81$ & $77-95$ & $47-61$ \\
\hline
\end{tabular}

Time waiting for the first patient

The surgical team waited at the start of the list between 7 and $45 \mathrm{~min}$ (mean $20 \mathrm{~min}$ ) for the first patient in the morning $(N=40)$ and between 7 and 32 min (mean $17 \mathrm{~min}$ ) in the afternoon $(N=37)$. The average time between sending and arrival in the anaesthetic room for the first case a.m./p.m. combined was 17 min (Fig. 1).

\section{Late starts}

Waiting for the first patient to arrive in theatre at the start of the morning list resulted in a late start for 43 (93\%) of the 46 morning lists for which "time into theatre" was recorded. On average this meant the surgical team waited for $22 \mathrm{~min}$ after the list was due to start for the first patient to arrive in theatre. The minimum time waited was $2 \mathrm{~min}$ and the maximum was $100 \mathrm{~min}(N=46)$.

Based on the mean time waiting for the first patient to arrive in theatres after the list should have started, the cost, estimated from theatre staff wages is on average $£ 88$ at the start of each morning list ( $£ 4$ per minute). In total $910 \mathrm{~min}$ or $15 \mathrm{~h}$ was wasted waiting for the list to start over the 3 -month study period. The estimated cost of this is $£ 3,640$.

\section{Discussion}

Our study adds reliability to the findings of earlier studies [11-15] and the generally held view of many surgeons and anaesthetist that operating theatres are less efficient than they could be. Moreover, we have shown that these inefficiencies are costly and represent a waste of resources that could be better spent on reducing waiting lists and improving opportunities for staff training. In particular, we have highlighted a key problem area, the arrival of the first patient to theatres which resulted in 93\% $(N=43)$ of the morning lists analysed $(N=46)$ starting late. This translated to a mean wait by the surgical team after the agreed start time of $22 \mathrm{~min}$ at an average cost of $£ 88$ per list. These findings are not isolated to gynaecology theatres, Ricketts et al. in a review of 151 elective orthopaedic lists found late starts in $94 \%$ of lists and an average start delay in morning lists of $24 \mathrm{~min}$ [13]. While Narain et al. in a computer audit of the use of theatre time reported $97 \%$ late starts in general surgery [15]. Both of these studies were carried out in the early 1990s, showing clearly the problem of late starts is a persistent one.

The total time wasted as a result of late starts in our study was $910 \mathrm{~min}$ or $15 \mathrm{~h}$ at a cost of $£ 3,640$ over the 3 -month study period. It is likely that this figure grossly underestimates the true cost of wasted time in our theatres as it relates only to morning list late starts and not to delays between cases or in starting the afternoon list. Equally it does not take account of lost tariffs for procedures which could be performed in the time wasted. We choose to focus on the morning list to give one clear goal for improving efficiency and also as it was felt delays occurring at the start of the list would have a knock on effect on the rest of the list and potentially the start of the afternoon list.

Our findings also show that it takes approximately $20 \mathrm{~min}$ to transport a patient from the ward to the
Fig. 1 Time waiting for the first case

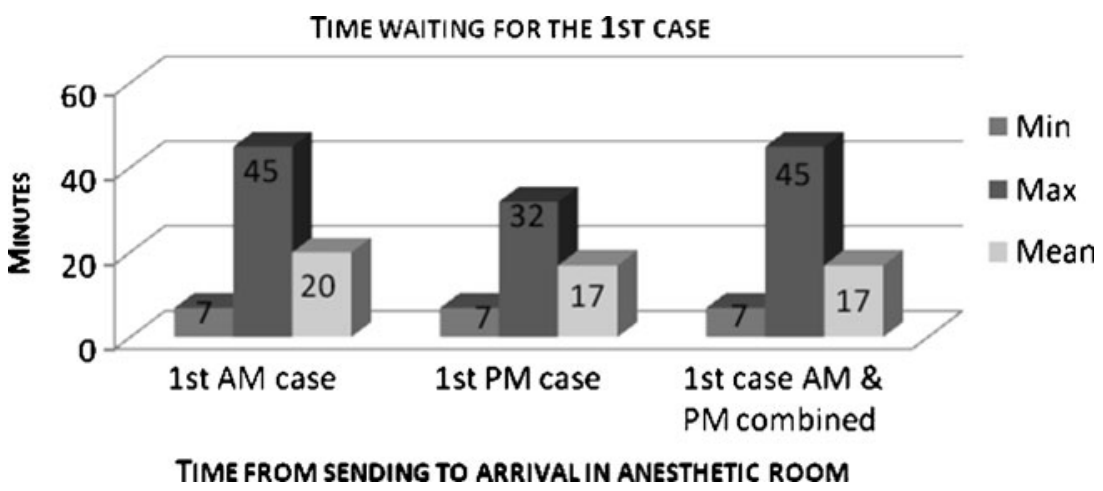


anaesthetic room, this is a robust finding as it was true of the both the first patient of the list and "time to send" overall and previous findings $[13,16]$. Also in keeping with previous findings time to send accounted for the greatest bulk of time in the patients' theatre journey apart from the procedure itself. Time for anaesthesia was relatively short on average taking just 9 min with a range from 3 to $40 \mathrm{~min}$. This information will prove valuable in theatre work planning where it would seem logical to implement an auditable standard, that to start with, at least the first patient is called for $30 \mathrm{~min}$ prior to the list start time. In support, Collantes et al. in a review of 1,241 trauma lists found the number of lists stating on time increased from $3.8 \%$ to $32 \%$ when patients were sent for 26 min earlier at 8.38 a.m. instead of 9.04 a.m. [16].

Moreover, our results show that on average procedures took $60 \mathrm{~min}$ to complete, this means over a 3-month period if lists started on time $15 \mathrm{~h}$ or 15 more procedures could be undertaken. Alternatively some of this time could be used for junior doctor surgical training as currently our findings show SpR's carried out only $23 \%$ of the operations analysed.

Although missing time point data was a limitation of this retrospective study, it does highlight another area were theatre efficiency could be improved. As pointed out by the audit commission's review of operating theatres [4] without accurate information on how theatres are running improvements and goals cannot be set. We would, therefore, recommend accurate recording of time points as a second auditable goal, facilitated by the introduction of a computerised monitoring system.

In conclusion sending for patients $30 \mathrm{~min}$ before the list is due to start and using computerised time point monitoring are auditable standards that could increase theatre efficiency and enable $15 \mathrm{~h}$ of currently wasted resources to be used to shorten waiting lists and enhance staff training opportunities.

Declaration of interest The authors report no conflicts of interest. The authors alone are responsible for the content and writing of the paper.

\section{References}

1. The NHS constitution. Department of health. January 2009. Retrieved online- http://www.dh.gov.uk/prod_consum_dh/groups/ dh_digitalassets/documents/digitalasset/dh_093442.pdf

2. The operating framework for the $\mathrm{NHS}^{-}$in England 2010/11. Department of health. December 2009. Retrieved online: http:// www.dh.gov.uk/prod_consum_dh/groups/dh_digitalassets/@dh/ @en/@ps/@sta/@perf/documents/digitalasset/dh_110159.pdf

3. Department of health hospital activity statistics (2009) Cancelled operations, NHS organisations in England, 2008-2009. http://www. performance.doh.gov.uk/hospitalactivity/data_requests/cancelled_ operations.htm

4. Audit Commission (2003) Operating theatres: review of national findings. HMSO, London

5. Rai M, Pandit JJ (2003) Day of surgery cancellations after nurse lead pre-assessment in an elective surgical centre: the first 2 years. Anaesthesia 61:768-776

6. Schofield WN, Rubin G, Piza M et al (2005) Cancellation of operations on the day of intended surgery at a major Australian referral hospital. Med J Aust 182:612-615

7. House of Commons Public Accounts Committee (2006) The use of operating theatres in Northern Ireland. Health and Personal Social Services, Seventh Report of Session 2005-6, London, HMSO

8. Tait AR, Voepel-Lewis T, Munro HM et al (1997) Cancellation of pediatric outpatient surgery: economic and emotional implications for patients and their families. J Clin Anaesth 9:213-219

9. Varsson B, Kimblad PO, Sjöberg T, Larsson S (2002) Patient reactions to cancelled or postponed heart operations. J Nurs Manag 10:75-81

10. Priorities and planning framework 2002/03. Department of health. December 2001. Retrieved online: http:/www.dh.gov.uk/en/ Publicationsandstatistics/Publications/PublicationsPolicyAnd Guidance/DH 4007616

11. Panditt JJ, Carey A (2006) Estimating the duration of common elective operations: implications for operating list management. Anaesthesia 58:692-699

12. Vinukondaiah K, Ananthakrishnan N, Ravishankar M (2000) Audit of operation theatre utilization in general surgery. Natl Med J India 13(3):118-121

13. Saha P, Pinjani A, Al-Shabibi et al (2009) Why are we wasting time in operating theatre? Int J health Plann Mgmt 24:225-232

14. Ricketts D, Hartley J, Patterson M, Harries W, Hitchin D (1994) An orthopaedic theatre timings survey. Ann R Coll Surg Engl 76:200-204

15. Narain P, Tackley R, Lee M, Clyne C (1992) A computer audit of the use of theatre time by a surgical team. Ann R Coll Surg Engl 7:166-168

16. Collantes E, Mauffrey C, Brewster M (2008) A review of 1241 trauma cases: a study of efficiency in trauma theatres. Injury Int $\mathrm{J}$ Care Injured 39:742-747 